DOI: 10.21127/yaoyigc20196001

\section{Nobel Prize in Chemistry}

On October 9, the Royal Swedish Academy of Sciences announced in Stockholm that the 2019 Nobel Prize in Chemistry was awarded to three scientists: American scientist John B. Goodenough, British scientist M. Stanley Whittingham and Japanese scientist Akira Yoshino in recognition of their research on lithium-ion batteries.

John B. Goodenough is a solid-state physicist and professor of mechanical engineering in University of Texas at Austin (Figure 1). He is the founder of lithium batteries and a member of the national academy of sciences and engineering. He has won the 2001 Japan Prize, the 2009 Fermi Award, the 2011 national medal of science and the 2014 Charles Stark Draper Prize. Professor Goodenough was born in Germany on July 25, 1922. He attended Groton school in Massachusetts at the age of 12. In 1940, he was admitted to Yale University to study mathematics at the age of 18 and later fought as a meteorologist in World War II. After graduating from college, he studied physics at University of Chicago, where he received a Ph.D. in physics from Clarence Zener, Professor of solid-state physics at University of Chicago. Now, he has won the Nobel Prize in chemistry at the age of 97 , making him the oldest Nobel laureate. Previously, the record was held by 96-year-old Arthur Ashkin, who won the 2018 Nobel Prize in physics. The main contribution of Professor Goodenough to lithium batteries is the development of lithium cobalt oxide and lithium iron phosphate batteries, which make batteries safer, more durable, smaller and more energy dense. Professor Goodenough, 97, still arrives in the lab at 8 a.m. every morning and hopes his research will help advance human development.

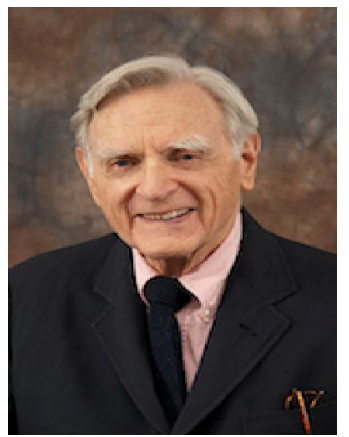

Figure 1 The portrait of John B. Goodenough.

M. Stanley Whittingham was born in the United Kingdom in 1941 (Figure 2). He received his bachelor's, master's and doctor's degrees from University of Oxford in 1964, 1967 and 1968. His research interests of the materials chemistry group focus on the preparation and chemical/physical properties of novel inorganic oxide materials. Wittingham's research is targeted at finding new materials that can boost energy storage to significantly advance the storage capacity of electrochemical devices. As early as 2015 , he was awarded to the Nobel Prize bellwether, Thomson Reuters Citation Laureate, for his pioneering research in the field of lithium-ion batteries. In 2018, he was elected as an academician of the national academy of engineering for his groundbreaking contribution in applying intercalation chemistry to energy storage materials. His main contribution in the field of lithium battery was to develop the first new lithium battery with

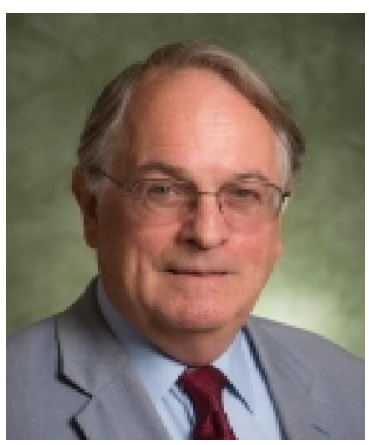

Figure 2 The portrait of M. Stanley Whittingham.

titanium sulfide as the positive electrode and lithium metal as the negative electrode, and to propose the concept of rechargeable lithium battery.

Yoshino Akira, a Japanese chemist and inventor of modern lithium-ion battery, has won the highest honor in the engineering world for the Global Energy Award and the Charles Stark Draper Award (Figure 3). In 1983, Yoshino employed lithium cobalt oxide $\left(\mathrm{LiCoO}_{2}\right.$, discovered by John $\mathrm{B}$. Goodenough) to develop the cathode, and developed the anode utilizing polyacetylene, which was the world's first prototype of a rechargeable lithium-ion battery. In 1985, he overcame many technical problems and completely eliminated lithium metal, thus establishing the basic concept of rechargeable lithium-containing alkaline lithium-ion battery. Yoshino Akira's lithium battery broke through the technical limitations of previous nickel-hydrogen batteries and opened the revolution in mobile electronic devices. Due to its high safety, stable energy output and reasonable price, lithium-ion batteries were firstly commercialized by SONY in 1991. In 2014, the National Academy of Engineering recognized John B. Goodenough, Rachid Yazami, and Yoshino Akira as the pioneering and leading fundamentals of modern lithium-ion batteries.

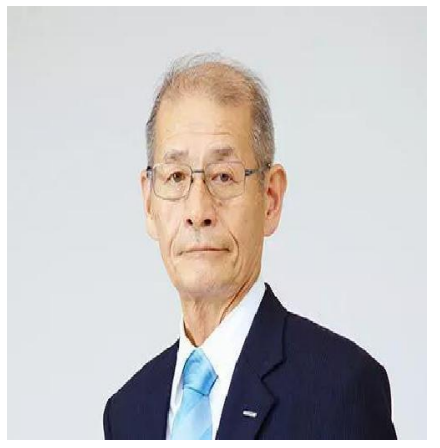

Figure 3 The portrait of Yoshino Akira.

Yoshino Akira was born in January 1948 in Osaka, Japan. In 1970, he graduated from Department of Petroleum Chemistry, Faculty of Engineering, Kyoto University. In 1972 he obtained a master's degree in engineering from Kyoto University. In 2005, he received a PhD in engineering from Osaka University. In 1972, Yoshino entered Asahi Kasei Industrial Co., Ltd. (now Asahi Kasei Co., Ltd.), and served as the AT\&T Technology Development Director in 1994. Three years later, he served as the head of the Asahi Kasei Corporation's Ion Secondary Battery Business Promotion Office. In 2003, he was promoted to Asahi Kasei Fellow. Since 2005, he has served as the director of the Yoshino Research Office of Asahi Kasei Co., Ltd. 